\title{
Autoregulatory Feedback Mechanism of P38MAPK/Caspase-8 in Photodynamic Therapy-Hydrophilic/Lipophilic Tetra- $\alpha$-(4-carboxyphenoxy) Phthalocyanine Zinc-Induced Apoptosis of Human Hepatocellular Carcinoma Bel-7402 Cells
}

\author{
Yu Wang, ${ }^{1}$ Chunhui Xia, ${ }^{1}$ Wei Chen, ${ }^{2}$ Yuhang Chen, ${ }^{1}$ Yiyi Wang, ${ }^{1}$ and Tao Li $^{1}$ \\ ${ }^{1}$ Basic Medicine Department, Qiqihar Medical College, Qiqihar 161006, China \\ ${ }^{2}$ College of Chemistry and Chemical Engineering, Qiqihar University, Qiqihar 161006, China
}

Correspondence should be addressed to Tao Li; litao888@sohu.com

Received 2 December 2013; Revised 9 February 2014; Accepted 9 February 2014; Published 31 March 2014

Academic Editor: Rudolf Steiner

Copyright (C) $2014 \mathrm{Yu}$ Wang et al. This is an open access article distributed under the Creative Commons Attribution License, which permits unrestricted use, distribution, and reproduction in any medium, provided the original work is properly cited.

Photodynamic therapy (PDT) is a novel and promising antitumor treatment. Our previous study showed that hydrophilic/lipophilic tetra- $\alpha$-(4-carboxyphenoxy) phthalocyanine zinc- (T $\alpha$ PcZn-) mediated PDT (T $\alpha$ PcZn-PDT) inhibits the proliferation of human hepatocellular carcinoma Bel-7402 cells by triggering apoptosis and arresting cell cycle. However, mechanisms of T $\alpha$ PcZn-PDTinduced apoptosis of Bel-7402 cells have not been fully clarified. In the present study, therefore, effect of T $\alpha$ PcZn-PDT on apoptosis, P38MAPK, p-P38MAPK, Caspase-8, Caspase-3, Bcl-2, Bid, Cytochrome c, and mitochondria membrane potential in Bel-7402 cells without or with P38MAPK inhibitor SB203580 or Caspase-8 inhibitor Ac-IEFD-CHO was investigated by haematoxylin and eosin (HE) staining assay, flow cytometry analysis of annexin V-FITC/propidium iodide (PI) double staining cells and 5, $5^{\prime}, 6,6^{\prime}$ tetrachloro-1,1',3,3'-tetraethylbenzimidazolylcarbocyanine iodide (JC-1), and immunoblot assay. We found that T $\alpha$ PcZn-PDT resulted in apoptosis induction, activation of P38MAPK, Caspase-8, Caspase-3, and Bid, downregulation of Bcl-2, release of Cytochrome $\mathrm{c}$ from mitochondria, and disruption of mitochondrial membrane potential in T $\alpha$ PcZn-PDT-treated Bel-7402 cells. In contrast, SB203580 or Ac-IEFD-CHO attenuated induction of apoptosis, activation of P38MAPK, Caspase-8, Caspase-3, and $\mathrm{Bid}$, downregulation of $\mathrm{Bcl}-2$, release of Cytochrome $\mathrm{c}$ from mitochondria, and disruption of mitochondrial membrane potential in T $\alpha$ PcZn-PDT-treated Bel-7402 cells. Taken together, we conclude that Caspase-3, Bcl-2, Bid, and mitochondria are involved in autoregulatory feedback of P38MAPK/Caspase-8 during T $\alpha$ PcZn-PDT-induced apoptosis of Bel-7402 cells.

\section{Introduction}

Photodynamic therapy (PDT), also known as photochemotherapy, is a developing strategy and has shown promising antitumor efficacy. It is based on the concept that photosensitizing drugs, when exposed to appropriate wavelength of light, are capable of resulting in photochemical destruction of tumors by yielding reactive oxygen species (ROS), such as singlet oxygen and free radicals [1-4]. Compared with traditional therapies, such as surgery and chemotherapy, the outstanding advantage of PDT is that it destroys tumor cells selectively because it is possible to expose the photosensitizer to light and to activate it specifically in the target tumor tissue.
Photosensitizers play a crucial role in PDT. Currently, although only a few photosensitizers (temoporfin, talaporfin, verteporfin, and 5-aminolevulinic acid), which are approved for antitumor treatment, have been proved to be effective in a wider spectrum of antitumor, they present various defects that stimulate the development of better photosensitizer candidates [5-7]. Phthalocyanines, consisting of a planar macrocycle with an $18 \pi$-electron system, are one of the most potential photosensitizer candidates because of the desirable electronic absorption and photophysical properties [8-10]. In addition, phthalocyanines with hydrophilic/lipophilic structure may become promising candidates for selectivephotosensitizers inasmuch as hydrophilic group contributes to the 
transport of drug in the body and lipophilic group redounds to the uptake of drug in cancer cells. Accumulating evidences have shown highly selective growth inhibitory effects of hydrophilic/lipophilic phthalocyanines-mediated PDT on a variety of cancer cells [11-13].

Apoptosis that plays a crucial role during development and maintenance of tissue homeostasis by eliminating old cells, unnecessary cells, and unhealthy cell is the process of programmed cell death that may occur in multicellular organisms. Apoptosis is characterized by morphologic and biochemical changes including chromatin condensation, cell shrinkage, nucleus and cytoplasm fragment, DNA fragmentation, and formation of membrane blebs and apoptotic bodies. Accumulating evidences clearly indicate that apoptosis is one key pathway in phthalocyanines-PDT process [11-13].

P38 mitogen-activated protein kinase (MAPK) is a member of the MAPK family of kinases that is responsive to stress stimuli (ionizing radiation, ultraviolet irradiation, oxidative stress, FAS ligand, and cytokines) and is involved in cell proliferation, differentiation, apoptosis, and autophagy. Nowadays, P38MAPK has been documented to play a crucial regulatory role in phthalocyanines-PDT-induced apoptosis of cancer cells $[14,15]$.

Caspases, a family of cysteine proteases, are central regulators of apoptosis signaling [16]. Initiator Caspase- 8 is closely coupled to proapoptotic signals. Once activated, Caspase- 8 cleaves and activates downstream effector Caspase-3, whose cleavage leads to the morphological and functional changes associated with apoptosis [17]. Nowadays, Caspase- 8 and Caspase- 3 have been documented to play a crucial regulatory role in phthalocyanines-PDT-induced apoptosis of cancer cells [18-21].

Apoptosis regulator $\mathrm{Bcl}-2$ is a family of evolutionarily related proteins. These proteins govern mitochondrial outer membrane permeabilization and comprise proapoptotic (Bax, Bid, Bak, etc.) and antiapoptotic (Bcl-2, Bcl-XL, Bcl-w, etc.) molecules. Recent studies have demonstrated that induction of proapoptotic proteins and inhibition of antiapoptotic proteins can be caused by phthalocyaninesPDT in apoptosis of cancer cells [11, 21, 22].

Mitochondrion is a membrane-enclosed organelle found in most eukaryotic cells. Cytochrome $\mathrm{c}$ is a small heme protein found loosely associated with the inner membrane of the mitochondrion. Membrane potential (also transmembrane potential or membrane voltage) is the difference in electrical potential between the interior and the exterior of a biological cell. Accumulated evidences have demonstrated that release of Cytochrome $\mathrm{c}$ from mitochondria and reduction of mitochondrial membrane potential appear to be key events in phthalocyanines-PDT-induced apoptosis of cancer cells $[19,20]$.

We found previously that tetra- $\alpha$-(4-carboxyphenoxy) phthalocyanine- (T $\alpha$ PcZn-) mediated PDT (T $\alpha$ PcZn-PDT) (Figure 1) resulted in the inhibition of proliferation and induction of apoptosis in Bel-7402 cells [11], which is one of the most widely used experiment models for hepatocellular carcinoma. However, mechanisms of T $\alpha$ PcZn-PDT-induced apoptosis of Bel-7402 cells have not been fully clarified. In the present study, the objective of our study is to investigate the autoregulatory feedback mechanism of P38MAPK/Caspase8 in T $\alpha$ PcZn-PDT-induced apoptosis of Bel-7402 cells. Based on in vitro model, we found that Caspase-3, Bcl-2, Bid, and mitochondria were involved in autoregulatory feedback of P38MAPK/Caspase- 8 during T $\alpha$ PcZn-PDT-induced apoptosis of Bel-7402 cells.

\section{Materials and Methods}

2.1. Materials. Anti-P38MAPK, anti-phos-P38MAPK, antiCaspase-8, anti-Caspase-3, anti-Bcl-2, anti-Bid, and antiCytochrome $c$ antibodies were purchased from Cell Signals (OH, USA). P38MAPK inhibitor SB203580 and Caspase8 inhibitor Ac-IEFD-CHO were obtained from Merck Calbiochem (Darmstadt, Germany). JC-I (5,5',6,6'-tetrachloro$1,1^{\prime}, 3,3^{\prime}$-tetraethylbenzimidazolylcarbocyanine iodide) Staining Kit was purchased from Genmed Scientifics (MA, U.S.A). Annexin-V-FLUOS Staining Kit was purchased from Roche (Basel, Switzerland). DMSO was purchased from Sigma (MO, USA). DMEM medium was purchased from Gibco (CA, USA). Fetal bovine serum was purchased from PAA (Coelbe, Germany). Penicillin was purchased from Harbin Pharmaceutical Group (Heilongjiang, China). Streptomycin was purchased from Dalian Merro Pharmaceutical (Liaoning, China). Polyvinylidene difluoride membrane (PVDF) membrane was purchased from Amersham Pharmacia Biotech (NJ, USA). T $\alpha$ PcZn was synthesized as described in our previous report [23]. The T $\alpha \mathrm{PcZn}$ stock solution was prepared in DMSO and stored at $4^{\circ} \mathrm{C}$ in the dark. When used, the stock solution was appropriately diluted to obtain the desired concentration with a final DMSO concentration of $0.1 \%$. All other chemicals and reagents were of analytic grade.

2.2. Cell Culture and Treatment. Hepatocellular carcinoma Bel-7402 cells were obtained from Harbin Medical University, China, and cultured in DMEM medium supplemented with $10 \%$ fetal bovine serum, $100 \mathrm{U} / \mathrm{mL}$ penicillin, and $100 \mathrm{mg} / \mathrm{L}$ streptomycin in a humidified atmosphere of $5 \% \mathrm{CO}_{2}$ at $37^{\circ} \mathrm{C}$. Bel-7402 cells in logarithmic growth phase were seeded in culture plates and incubated for $24 \mathrm{~h}$ in a humidified atmosphere of $5 \% \mathrm{CO}_{2}$ at $37^{\circ} \mathrm{C}$. After being rinsed with phosphatebuffered saline, the cells were treated with $\mathrm{T} \alpha \mathrm{PcZn}$ stock solution diluted in medium for $2.5 \mathrm{~h}$ at $37^{\circ} \mathrm{C}$ in the presence or absence of SB203580 or Ac-IEFD-CHO. Then the cells were irradiated with a SS-B instrument (Wuxi Holyglow Physiotherapy Instrument Co., Ltd., Jiangsu, China) emitting red light within the wavelength range of 600 to $700 \mathrm{~nm}$. The light dose was about $53.7 \mathrm{~J} / \mathrm{cm}^{2}$. Thereafter, cells were harvested at $3 \mathrm{~h}$. Control cells were treated with $0.1 \%$ DMSO under the same conditions.

2.3. Cell Morphology Assay. At $3 \mathrm{~h}$ posttreatment, Bel-7402 cells on a glass slide within 6-well culture plates were fixed with $10 \%$ formaldehyde for $15 \mathrm{~min}$, washed with phosphatebuffered saline, and stained with haematoxylin and eosin (HE). Cells morphology was then observed under IX70 inverted microscope (Olympus, Tokyo, Japan). 


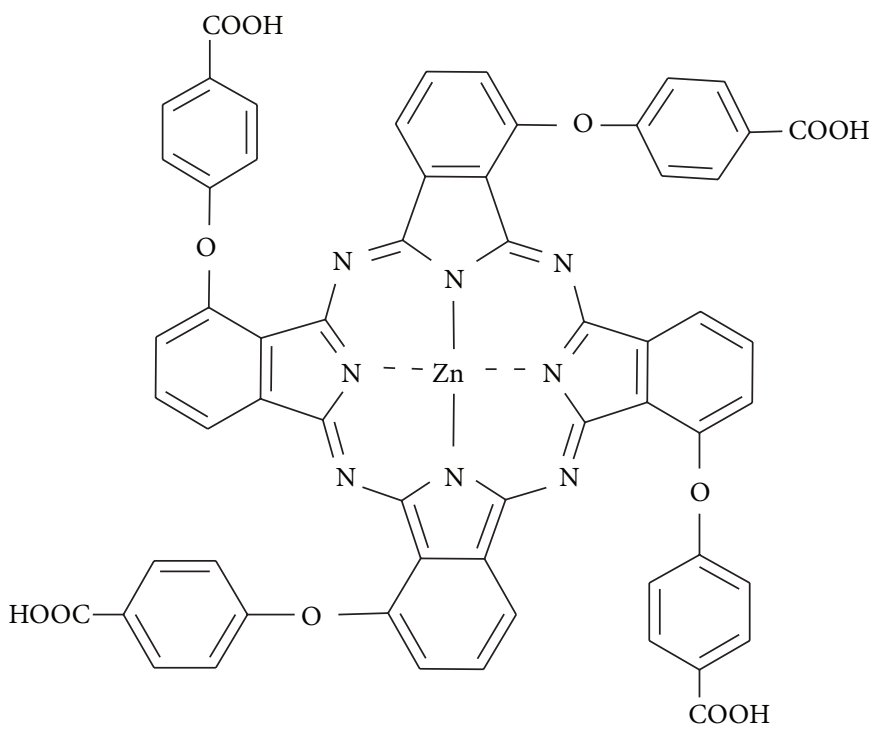

FIGURE 1: Chemical structure of T $\alpha$ PcZn [11].

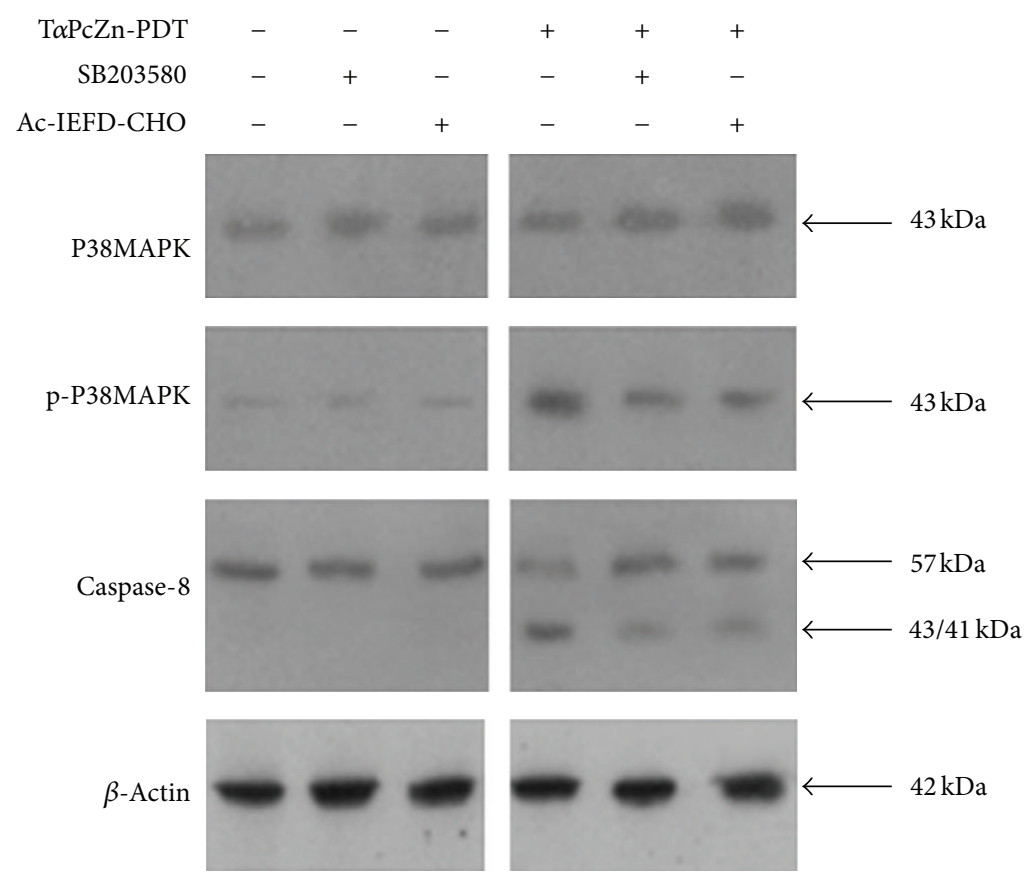

Figure 2: Effect of T $\alpha$ PcZn-PDT on P38MAPK, p-P38MAPK, and Caspase-8, respectively, without or with SB203580 or Ac-IEFD-CHO in $\mathrm{T} \alpha$ PcZn-PDT-induced apoptosis of Bel-7402 cells analyzed by immunoblot assay. Bel-7402 cells were pretreated with T $\alpha \mathrm{PcZn}(54 \mu \mathrm{M})$ in the absence or presence of SB203580 $(10 \mu \mathrm{M})$ or Ac-IEFD-CHO $(10 \mu \mathrm{M})$ for $2.5 \mathrm{~h}$, exposed to red-light irradiation $\left(53.7 \mathrm{~J} / \mathrm{cm}^{2}\right)$, and then incubated for $3 \mathrm{~h}$. Expression of P38MAPK, p-P38MAPK, and Caspase- 8 was analyzed by immunoblot assay.

2.4. Flow Cytometry Analysis Of Annexin V-FITC/PI Double Stained Cells for Apoptosis. Confirmation of apoptosis was determined by measurement of externalized phosphatidylserine residues as detected using annexin V-FITC. The harvested Bel-7402 cells were collected and washed with ice-cold phosphate-buffered saline and then suspended in $500 \mu \mathrm{L}$ of annexin $\mathrm{V}$ binding buffer A. $100 \mu \mathrm{L}$ aliquot was taken, $2 \mu \mathrm{L}$ of annexin $\mathrm{V}$-FITC and $2 \mu \mathrm{L}$ of propidium iodide (PI) were added, and the mixture was incubated for $5 \mathrm{~min}$ at room temperature in the dark. After the addition of $400 \mu \mathrm{L}$ of binding buffer, $1 \times 10^{4}$ cells were analyzed on a FACSCAN flow cytometer (Becton Dickinson, CA, USA) by using CellQuest software. The results are shown as a dot plot graph. In each graph, the percentages of viable cells, early apoptotic cells, and late apoptotic cells are, respectively, indicated in lower-left, lower-right, and upper-right quadrant; the $y$-axis corresponds to relative PI staining; the $x$-axis corresponds to the log of the FITC signal. 
Control treatment

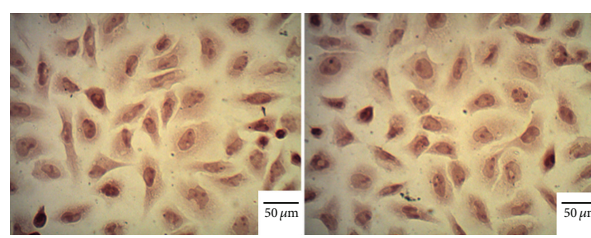

T $\alpha$ PcZn-PDT

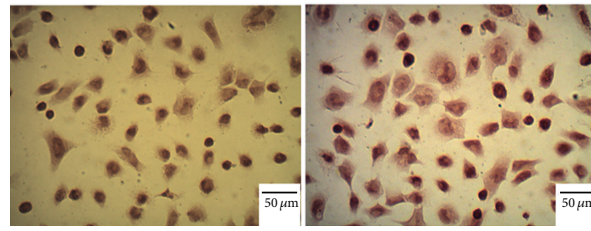

(a)
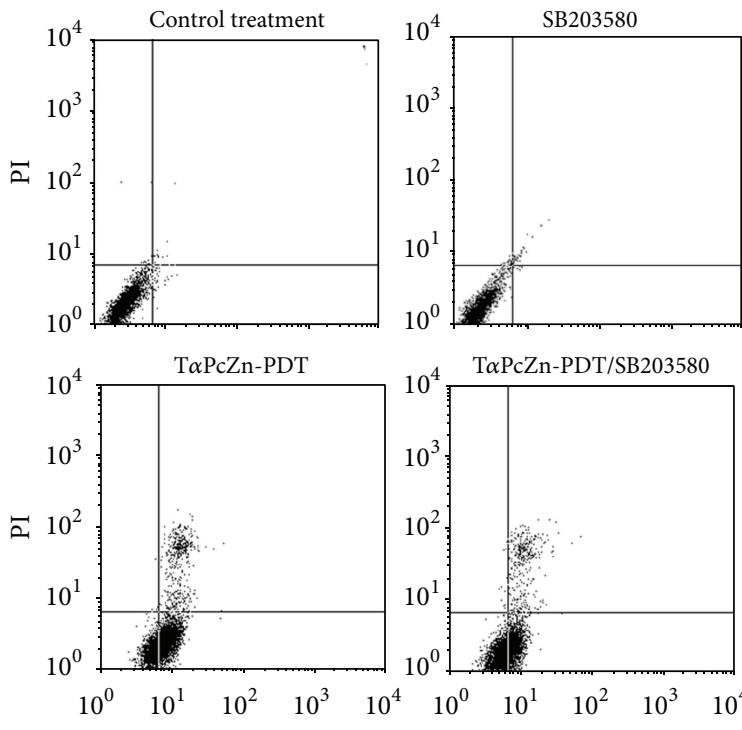

FITC

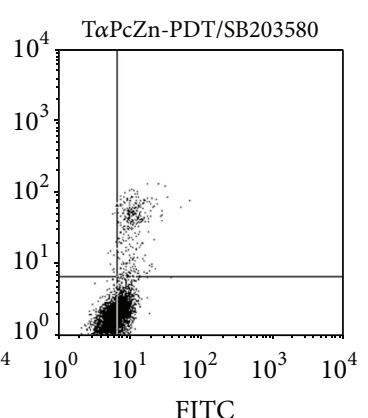

Ac-IEFD-CHO

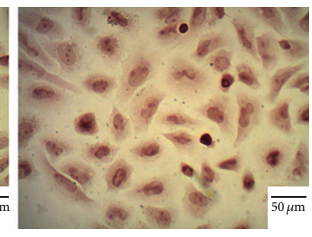

T $\alpha$ PcZn-PDT/Ac-IEFD-CHO

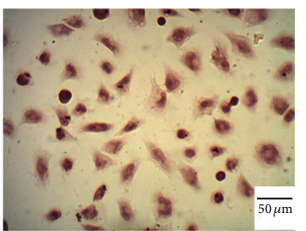

(b)
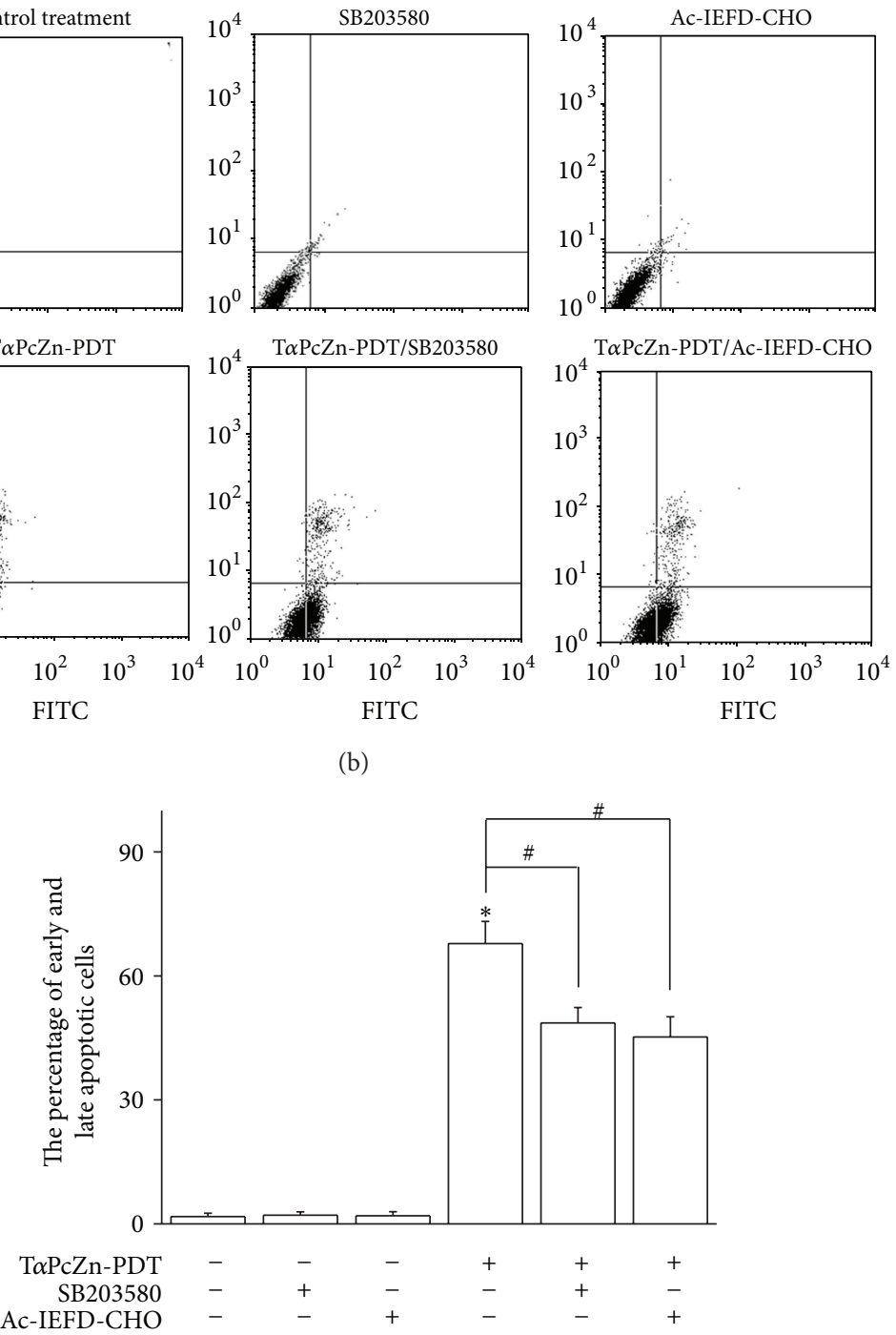

(c)

FIGURE 3: Effect of T $\alpha$ PcZn-PDT on apoptosis of Bel-7402 cells in the absence or presence of SB203580 or Ac-IEFD-CHO. Bel-7402 cells were pretreated with $\mathrm{T} \alpha \mathrm{PcZn}(54 \mu \mathrm{M})$ in the absence or presence of SB203580 (10 $\mu \mathrm{M})$ or Ac-IEFD-CHO (10 $\mu \mathrm{M})$ for $2.5 \mathrm{~h}$, exposed to redlight irradiation $\left(53.7 \mathrm{~J} / \mathrm{cm}^{2}\right)$, and then incubated for $3 \mathrm{~h}$. The morphology of apoptotic cells was analyzed by HE staining assay (a), and the percentage of apoptotic cells was assayed by flow cytometry analysis of annexin V-FITC/PI double stained cells (b and c). Bars under each panel represent $50 \mu \mathrm{m}$. Values presented are representative of three independent experiments (means \pm S.D.; ${ }^{*} P<0.05$, compared with control treatment; ${ }^{\#} P<0.05$, compared with T $\alpha$ PcZn-PDT treatment). 


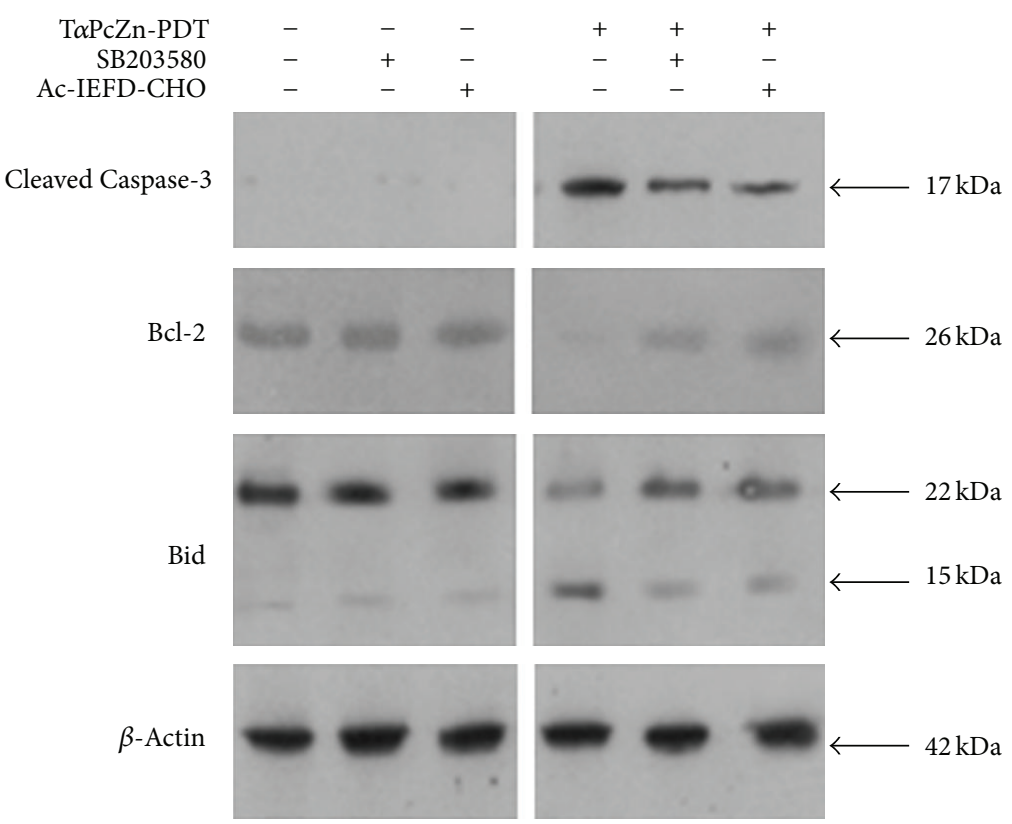

FIgURE 4: Effect of T $\alpha$ PcZn-PDT on Caspase-3, Bcl-2, and Bid, respectively, without or with SB203580 or Ac-IEFD-CHO in T $\alpha$ PcZn-PDTinduced apoptosis of Bel-7402 cells analyzed by immunoblot assay. Bel-7402 cells were pretreated with $\mathrm{T} \alpha \mathrm{PcZn}(54 \mu \mathrm{M})$ in the absence or presence of SB203580 $(10 \mu \mathrm{M})$ or Ac-IEFD-CHO $(10 \mu \mathrm{M})$ for $2.5 \mathrm{~h}$, exposed to red-light irradiation $\left(53.7 \mathrm{~J} / \mathrm{cm}^{2}\right)$, and then incubated for $3 \mathrm{~h}$. Expression of cleaved Caspase-3, Bcl-2, and Bid was analyzed by immunoblot assay.

2.5. JC-1 Assay for Mitochondrial Membrane Potential. Mitochondrial membrane potential was detected using JC-1 fluorescent dye by flow cytometry. The harvested cells were incubated with fresh culture medium containing JC-1 dye $(2.5 \mathrm{ug} / \mathrm{mL})$ for $20 \mathrm{~min}$ at $37^{\circ} \mathrm{C}$ in the dark, and then about $1 \times 10^{4}$ cells were analyzed on a flow cytometer by using CellQuest software. The results are shown as a dot plot graph. In each graph, the $y$-axis corresponds to JC-1 oligomerassociated red fluorescence, the $x$-axis corresponds to JC-1 monomer-associated green fluorescence, and the shift down of fluorescence from red to green indicates the collapse of mitochondrial membrane potential.

2.6. Immunoblot Assay. All immunoblots were performed using sodium dodecyl sulfate-polyacrylamide gel electrophoresis (SDS-PAGE) Bis-Tris gel electrophoresis as outlined by the supplier. For total cellular protein, Bel-7402 cells were lysed in buffer containing $25 \mathrm{mM}$ HEPES, pH 7.5, 0.3 M NaCl, $1.5 \mathrm{mM} \mathrm{MgCl}_{2}, 0.2 \mathrm{mM}$ EDTA, $0.1 \%$ Triton X100, $20 \mathrm{mM} \beta$-glycerophosphate, $0.5 \mathrm{mM}$ DTT, $1 \mathrm{mM}$ sodium orthovanadate, $0.1 \mu \mathrm{M}$ okadaic acid, and $1 \mathrm{mM}$ phenylmethylsulfonyl fluoride. Equal amounts of lysate protein ran on $12 \%$ SDS-PAGE and electrophoretically transferred to PVDF membrane. After blocking, the blots were incubated with specific primary antibodies (anti-P38MAPK, anti-phosP38MAPK, anti-Caspase-3, anti-Caspase-8, anti-Bcl-2, and anti-Bid antibodies) overnight at $4^{\circ} \mathrm{C}$ and further incubated for $1 \mathrm{~h}$ with horseradish peroxidase-conjugated respective secondary antibody. Bound antibodies were detected by enhanced chemiluminescence kit with Lumino Image Analyzer (Founder, Beijing, China). The mitochondria and cytosolic fractions isolated from the cells were collected for immunoblot assay of Cytochrome $c$ as previously described [24]. The Cytochrome c protein was assayed using an antiCytochrome $\mathrm{c}$ antibody.

2.7. Statistical Analysis. Values are means \pm S.D. of three independent experiments. Statistical significance was determined using Student's unpaired two-tailed $t$-test. $P$ value less than 0.05 was considered significant in all cases.

\section{Results}

3.1. Autoregulatory Feedback of P38MAPK/Caspase-8 Is Essen-

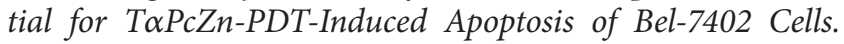
Our previous study showed that T $\alpha$ PcZn-PDT apparently induced apoptosis of Bel-7402 cells [11]. To evaluate whether P38MAPK and Caspase- 8 are involved in T $\alpha$ PcZn-PDTinduced apoptosis of Bel-7402 cells, effect of T $\alpha$ PcZn-PDT on P38MAPK, p-P38MAPK, and Caspase-8, respectively, was investigated by immunoblot assay in the present study. Compared with the control treatment, T $\alpha \mathrm{PcZn}-\mathrm{PDT}$ resulted in little effect on P38MAPK, upregulation of p-P38MAPK, and activation of active Caspase- 8 (Figure 2), suggesting that active P38MAPK and Caspase- 8 might modulate T $\alpha$ PcZnPDT-induced apoptosis of Bel-7402 cells.

To determine whether attenuation of P38MAPK, pP38MAPK, and Caspase-8 influences Bel-7402 cells in T $\alpha$ PcZn-PDT-induced apoptosis, we used the P38MAPK inhibitor SB203580 or Caspase-8 inhibitor Ac-IEFD-CHO. Compared with T $\alpha$ PcZn-PDT treatment, SB203580 resulted 


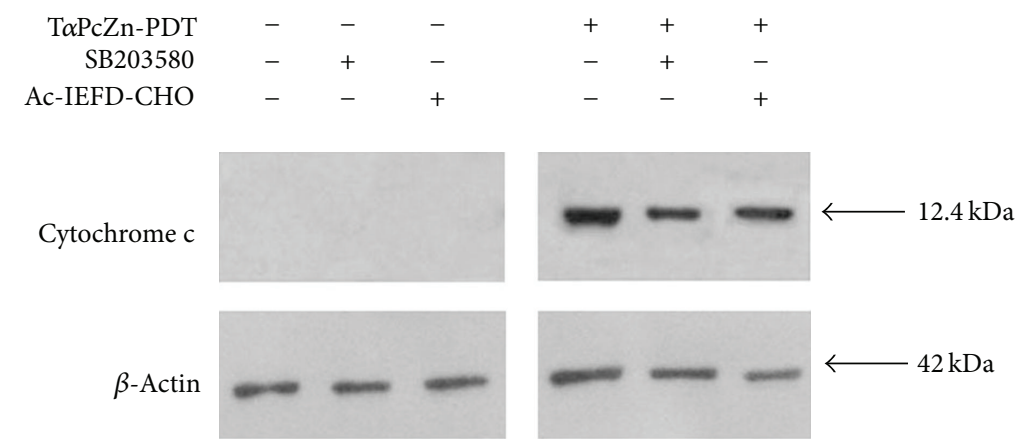

(a)
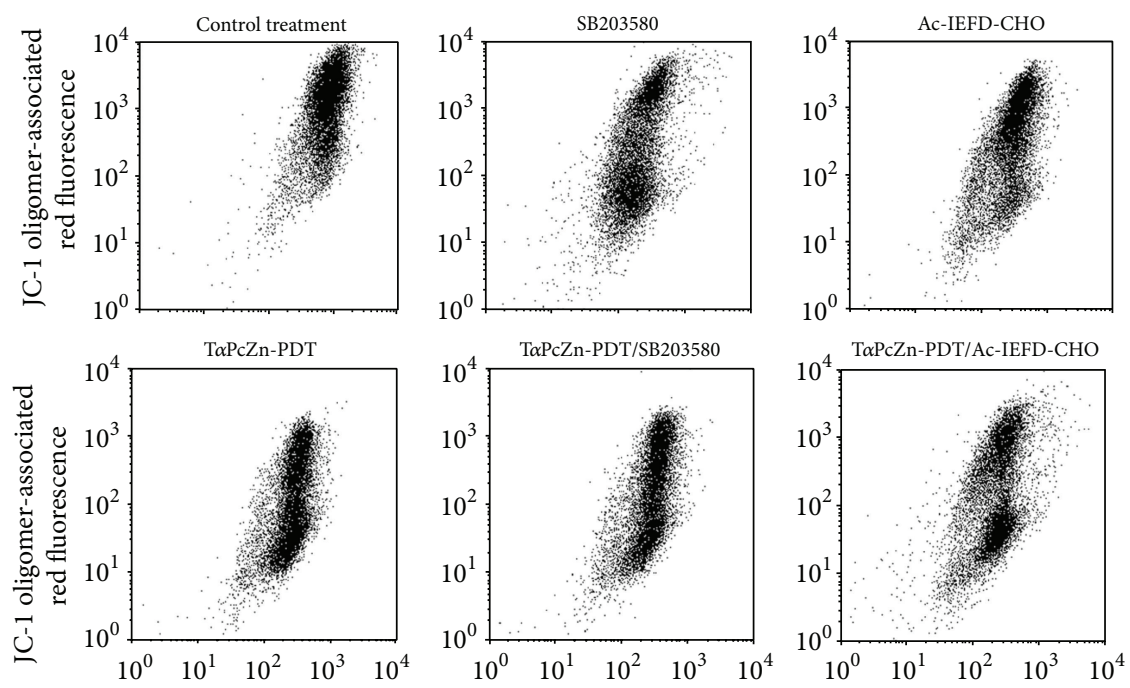

JC-1 monomer-associated green fluorescence

JC-1 monomer-associated green fluorescence

(b)
JC-1 monomer-associated green fluorescence

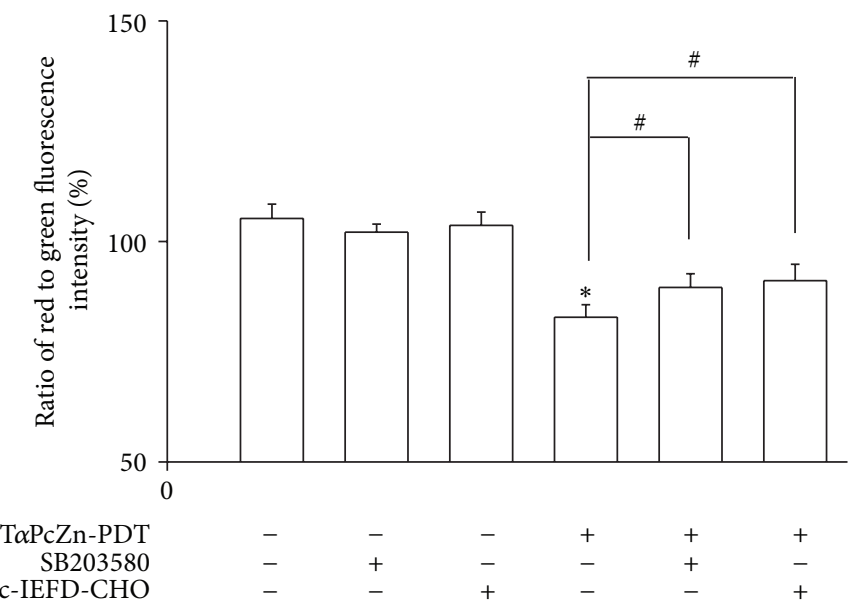

(c)

FIGURE 5: Effect of T $\alpha$ PcZn-PDT on mitochondria of Bel-7402 cells in the absence or presence of SB203580 or Ac-IEFD-CHO. Bel-7402 cells were pretreated with T $\alpha \operatorname{PcZn}(54 \mu \mathrm{M})$ in the absence or presence of SB203580 $(10 \mu \mathrm{M})$ or Ac-IEFD-CHO $(10 \mu \mathrm{M})$ for $2.5 \mathrm{~h}$, exposed to red-light irradiation $\left(53.7 \mathrm{~J} / \mathrm{cm}^{2}\right)$, and then incubated for $3 \mathrm{~h}$. Expression of Cytochrome $\mathrm{c}$ was analyzed by immunoblot assay (a), and mitochondria membrane potential (b) and ratio of red to green fluorescence intensity (c) in Bel-7402 cells were determined by JC-1 assay of flow cytometry, respectively. Values presented are representative of three independent experiments (means \pm S.D.; ${ }^{*} P<0.05$, compared with control treatment; ${ }^{\#} P<0.05$, compared with T $\alpha$ PcZn-PDT treatment). 
in little effect on P38MAPK and downregulation of pP38MAPK, and Ac-IEFD-CHO led to downregulation of $43 / 41-\mathrm{kDa}$ subunit of active Caspase- 8 in T $\alpha$ PcZn-PDTtreated Bel-7402 cells (Figure 2), suggesting that attenuation of active P38MAPK and Caspase-8 might be involved in T $\alpha$ PcZn-PDT-induced apoptosis of Bel-7402 cells.

To confirm whether Caspase-8 or P38MAPK regulates apoptosis in T $\alpha$ PcZn-PDT-treated Bel-7402 cells, effect of SB203580 or Ac-IEFD-CHO on apoptosis, respectively, was investigated by several ways in the present study. Firstly, the morphological characteristics of apoptotic cells were assessed by HE staining assay. Compared with control cells, cells treated with T $\alpha$ PcZn-PDT apparently exhibited morphological characteristics of apoptotic cells, such as cell shrinkage, chromatin condensation, nucleus and cytoplasm fragment, and membrane blebs formation (Figure 3(a)). However, compared with T $\alpha$ PcZn-PDT treatment, SB203580 or Ac-IEFD-CHO resulted in less morphological characteristics of apoptosis in T $\alpha$ PcZn-PDT-treated cells (Figure 3(a)). Furthermore, apoptosis of cells was quantitatively evaluated by flow cytometry analysis of annexin V-FITC/PI double staining cells. Compared with control treatment, T $\alpha$ PcZnPDT apparently induced cells apoptosis (Figures 3(b) and $3(c))$. However, compared with T $\alpha$ PcZn-PDT treatment, SB203580 or Ac-IEFD-CHO resulted in less effect of apoptosis on T $\alpha$ PcZn-PDT-treated cells (Figures 3(b) and 3(c)). These results indicate that active P38MAPK and Caspase-8 are essential for T $\alpha$ PcZn-PDT-induced apoptosis of Bel-7402 cells.

To determine whether P38MAPK regulates Caspase- 8 and whether Caspase-8 regulates P38MAPK, effect of SB203580 on Caspase-8 and effect of Ac-IEFD-CHO on P38MAPK in T $\alpha$ PcZn-PDT-treated Bel-7402 cells were, respectively, investigated by immunoblot assay in the present study. Compared with T $\alpha$ PcZn-PDT treatment, SB203580 downregulated 43/41-kDa subunit of active Caspase- 8 and Ac-IEFD-CHO downregulated p-P38MAPK in T $\alpha$ PcZnPDT-treated Bel-7402 cells (Figure 2), suggesting that autoregulatory feedback of P38MAPK/Caspase-8 is involved in T $\alpha$ PcZn-PDT-induced apoptosis of Bel-7402 cells. All of the above results suggest that autoregulatory feedback of P38MAPK/Caspase-8 is essential for T $\alpha$ PcZn-PDT-induced apoptosis of Bel-7402 cells.

3.2. Caspase-3 and Bcl-2 Family Proteins Are Involved in Autoregulatory Feedback of P38MAPK/Caspase- 8 in T $\alpha$ PcZnPDT-Induced Apoptosis of Bel-7402 Cells. To determine whether Caspase-3 and Bcl-2 family are involved in autoregulatory feedback of P38MAPK/Caspase- 8 during T $\alpha \mathrm{PcZn}$ PDT-induced apoptosis of Bel-7402 cells, effect of T $\alpha$ PcZnPDT on Caspase-3, Bcl-2, and Bid, respectively, in the absence or presence of SB203580 or Ac-IEFD-CHO was investigated by immunoblot assay in the present study. Compared with the control treatment, T $\alpha$ PcZn-PDT resulted in upregulation of 17-kDa subunit of active Caspase-3, downregulation of Bcl-2, and upregulation of $15-\mathrm{kDa}$ subunit of active Bid (Figure 4), suggesting that Caspase-3, Bcl-2, and Bid are involved in
T $\alpha$ PcZn-PDT-induced apoptosis of Bel-7402 cells. Furthermore, compared with the T $\alpha$ PcZn-PDT treatment, SB203580 or Ac-IEFD-CHO resulted in downregulation of $17-\mathrm{kDa}$ subunit of active Caspase-3, upregulation of $\mathrm{Bcl}-2$, and downregulation of $15-\mathrm{kDa}$ subunit of active Bid (Figure 4), suggesting that autoregulatory feedback of P38MAPK/Caspase- 8 might regulate Caspase- $3, \mathrm{Bcl}-2$, and Bid in T $\alpha \mathrm{PcZn}$-PDT-induced apoptosis of Bel-7402 cells.

3.3. Mitochondrion Is Involved in Autoregulatory Feedback of P38MAPK/Caspase-8 in TaPcZn-PDT-Induced Apoptosis of Bel-7402 Cells. To determine whether mitochondrion is involved in autoregulatory feedback of P38MAPK/Caspase8 during T $\alpha$ PcZn-PDT-induced apoptosis of Bel-7402 cells, effect of T $\alpha$ PcZn-PDT on Cytochrome $c$ and mitochondria membrane potential, respectively, in the absence or presence of SB203580 or Ac-IEFD-CHO was investigated by immunoblot assay and JC-1 assay of flow cytometry in the present study. Compared with the control treatment, $\mathrm{T} \alpha \mathrm{PcZn}$-PDT resulted in upregulation of Cytochrome $\mathrm{c}$ and a decrease in ratio of red to green fluorescence intensity, suggesting that release of Cytochrome $\mathrm{c}$ from mitochondria and disruption of mitochondrial membrane potential are involved in T $\alpha$ PcZn-PDT-induced apoptosis of Bel-7402 cells (Figure 5). Furthermore, compared with the T $\alpha \mathrm{PcZn}$ PDT treatment, SB203580 or Ac-IEFD-CHO resulted in downregulation of Cytochrome $\mathrm{c}$ and an increase in ratio of red to green fluorescence intensity (Figure 5), suggesting that autoregulatory feedback of P38MAPK/Caspase- 8 might regulate mitochondria in T $\alpha \mathrm{PcZn}$-PDT-induced apoptosis of Bel-7402 cells.

\section{Discussion}

Accumulated evidences have suggested that P38MAPK and Caspase- 8 are involved in phthalocyanines-PDT-induced apoptosis of cancer cells [14, 15, 18]. Our previous study has showed that T $\alpha$ PcZn-PDT can apparently induce apoptosis of Bel-7402 cells [11]. However, it is unclear whether autoregulatory feedback of P38MAPK/Caspase-8 is essential for T $\alpha$ PcZn-PDT-induced apoptosis of Bel-7402 cells. Therefore, effect of T $\alpha$ PcZn-PDT on P38MAPK, p-P38MAPK, and Caspase- 8 , respectively, in T $\alpha$ PcZn-PDTinduced apoptosis of Bel-7402 cells without or with SB203580 or Ac-IEFD-CHO was firstly investigated in the present study. The result showed that T $\alpha$ PcZn-PDT caused activation of P38MAPK and Caspase-8, but SB203580 or Ac-IEFD-CHO, respectively, resulted in downregulation of active P38MAPK and Caspase-8, suggesting that activation of P38MAPK and Caspase- 8 might be involved in T $\alpha$ PcZn-PDT-induced apoptosis of Bel-7402 cells. Furthermore, to confirm whether Caspase- 8 and P38MAPK regulate apoptosis in T $\alpha$ PcZn-PDT-treated Bel-7402 cells, effect of SB203580 or Ac-IEFD-CHO on apoptosis, respectively, was investigated in the present study. The results showed that T $\alpha$ PcZn-PDT apparently induced apoptosis, but SB203580 or Ac-IEFDCHO attenuated apoptosis of Bel-7402 cells in T $\alpha$ PcZnPDT-treated cells, suggesting that activated P38MAPK and 
Caspase- 8 are essential for T $\alpha$ PcZn-PDT-induced apoptosis of Bel-7402 cells. Accumulated evidences have suggested that Caspase- 8 regulates P38MAPK or P38MAPK regulates Caspase-8 in drugs-induced apoptosis of cancer cells [25-27]. However, it is unclear whether autoregulatory feedback of P38MAPK/Caspase- 8 is involved in T $\alpha$ PcZn-PDT-induced apoptosis of Bel-7402 cells. Therefore, effect of SB203580 on Caspase- 8 and effect of Ac-IEFD-CHO on P38MAPK were further investigated in the present study. The results showed that SB203580 attenuated activation of Caspase-8 and that Ac-IEFD-CHO attenuated activation of P38MAPK in T $\alpha$ PcZn-PDT-induced apoptosis of Bel-7402 cells, suggesting that autoregulatory feedback of P38MAPK/Caspase-8 might modulate T $\alpha$ PcZn-PDT-induced apoptosis of Bel-7402 cells. All of the above results suggest that autoregulatory feedback of P38MAPK/Caspase-8 is essential for T $\alpha$ PcZn-PDTinduced apoptosis of Bel-7402 cells.

Several studies have demonstrated that Caspase-3, Bcl-2 family proteins, and mitochondria are involved in phthalocyanines-PDT-induced apoptosis of cancer cells [18-22]. Our previous study has showed that $\mathrm{Bcl}-2$ is involved in T $\alpha \mathrm{PcZn}$ PDT-induced apoptosis of Bel-7402 cells [11]. However, it is not clear whether Caspase-3, Bid, and mitochondria were involved in T $\alpha$ PcZn-PDT-induced apoptosis of Bel7402 cells. Therefore, effect of T $\alpha$ PcZn-PDT on Caspase-3, Bid, Cytochrome c, and mitochondria membrane potential, respectively, in T $\alpha$ PcZn-PDT-induced apoptosis of Bel-7402 cells was firstly investigated in the present study. The result showed that T $\alpha$ PcZn-PDT apparently resulted in activation of Caspase-3 and Bid, release of Cytochrome $\mathrm{c}$ from mitochondria, and disruption of mitochondrial membrane potential, suggesting that Caspase-3, Bid, and mitochondria might modulate T $\alpha$ PcZn-PDT-induced apoptosis of Bel-7402 cells. Accumulated evidences have suggested that Caspase-3, Bcl-2 family proteins, and mitochondria are downstream of P38MAPK [27-30] or Caspase-8 [31-33]. However, it is unclear whether autoregulatory feedback of P38MAPK/Caspase- 8 can regulate Caspase-3, Bcl-2, Bid, and mitochondria in T $\alpha$ PcZn-PDT-induced apoptosis of Bel7402 cells. Therefore, effect of T $\alpha$ PcZn-PDT on Caspase-3, Bcl-2, Cytochrome c, and mitochondrial membrane potential, respectively, in the presence of SB203580 or Ac-IEFD$\mathrm{CHO}$ was investigated in the present study. The results showed that SB203580 or Ac-IEFD-CHO attenuated activation of Caspase- 3 and Bid, downregulation of Bcl-2, release of Cytochrome $c$ from mitochondria, and disruption of mitochondrial membrane potential, suggesting that Caspase3 , Bcl-2 family proteins, and mitochondria are involved in autoregulatory feedback of P38MAPK/Caspase-8 during T $\alpha$ PcZn-PDT-induced apoptosis of Bel-7402 cells.

Taken together, our findings demonstrate that Caspase3 , Bcl-2, Bid, and mitochondria are involved in autoregulatory feedback of P38MAPK/Caspase-8 during T $\alpha$ PcZn-PDTinduced apoptosis of Bel-7402 cells.

\section{Conflict of Interests}

The authors do not have any conflict of interests with the content of the paper.

\section{Acknowledgment}

This project was financially supported by the Natural Science Foundation of Heilongjiang Province (no. ZD201318).

\section{References}

[1] A. Kamkaew, S. H. Lim, H. B. Lee, L. V. Kiew, L. Y. Chung, and K. Burgess, "BODIPY dyes in photodynamic therapy," Chemical Society Reviews, vol. 42, pp. 77-88, 2013.

[2] R. Vallinayagam, J. Weber, and R. Neier, "Novel bioconjugates of aminolevulinic acid with vitamins," Organic Letters, vol. 10, no. 20, pp. 4453-4455, 2008.

[3] H. Xu, C. Liu, J. Mei et al., "Effects of light irradiation upon photodynamic therapy based on 5-aminolevulinic acidgold nanoparticle conjugates in K562 cells via singlet oxygen generation," International Journal of Nanomedicine, vol. 7, pp. 5029-5038, 2012.

[4] L. Lilge, M. Portnoy, and B. C. Wilson, "Apoptosis induced in vivo by photodynamic therapy in normal brain and intracranial tumour tissue," British Journal of Cancer, vol. 83, no. 8, pp. 1110$1117,2000$.

[5] H. Lu, W. Syu, N. Nishiyama, K. Kataoka, and P. Lai, "Dendrimer phthalocyanine-encapsulated polymeric micellemediated photochemical internalization extends the efficacy of photodynamic therapy and overcomes drug-resistance in vivo," Journal of Controlled Release, vol. 155, no. 3, pp. 458-464, 2011.

[6] S. Cui, D. Yin, Y. Chen et al., "In vivo targeted deep-tissue photodynamic therapy based on near-infrared light triggered upconversion nanoconstruct," ACS Nano, vol. 7, pp. 676-688, 2013.

[7] M. Laranjo, A. C. Serra, M. Abrantes et al., "2-bromo-5hydroxyphenylporphyrins for photodynamic therapy: photosensitization efficiency, subcellular localization and in vivo studies," Photodiagnosis and Photodynamic Therapy, vol. 10, pp. 51-61, 2013.

[8] Z. A. Carneiro, J. C. B. de Moraes, F. P. Rodrigues et al., "Photocytotoxic activity of a nitrosyl phthalocyanine ruthenium complex-a system capable of producing nitric oxide and singlet oxygen," Journal of Inorganic Biochemistry, vol. 105, no. 8, pp. 1035-1043, 2011.

[9] K. Sutoris, J. Rakusan, M. Karaskova et al., "Novel topical photodynamic therapy of prostate carcinoma using hydroxyaluminum phthalocyanine entrapped in liposomes," Anticancer Research, vol. 33, pp. 1563-1568, 2013.

[10] S. G. Kimani, T. A. Shmigol, S. Hammond et al., "Fully protected glycosylated zinc (II) phthalocyanine shows high uptake and photodynamic cytotoxicity in MCF-7 cancer cells," Photochemistry and Photobiology, vol. 89, pp. 139-149, 2013.

[11] C. Xia, Y. Wang, W. Chen, W. Yu, B. Wang, and T. $\mathrm{Li}$, "New hydrophilic/lipophilic tetra- $\alpha$-(4-carboxyphenoxy) phthalocyanine zinc-mediated photodynamic therapy inhibits the proliferation of human hepatocellular carcinoma Bel-7402 cells by triggering apoptosis and arresting cell cycle," Molecules, vol. 16, no. 2, pp. 1389-1401, 2011.

[12] Z. Zhao, P. Chan, H. Li et al., "Highly selective mitochondriatargeting amphiphilic silicon(IV) phthalocyanines with axially ligated rhodamine B for photodynamic therapy," Inorganic Chemistry, vol. 51, no. 2, pp. 812-821, 2012.

[13] R. M. Amin, C. Hauser, I. Kinzler, A. Rueck, and C. ScalfiHapp, "Evaluation of photodynamic treatment using aluminum 
phthalocyanine tetrasulfonate chloride as a photosensitizer: new approach," Photochemical and Photobiological Sciences, vol. 11, pp. 1156-1163, 2012.

[14] L. Xue, J. He, and N. L. Oleinick, "Promotion of photodynamic therapy-induced apoptosis by stress kinases," Cell Death and Differentiation, vol. 6, no. 9, pp. 855-864, 1999.

[15] C. M. Whitacre, D. K. Feyes, T. Satoh et al., "Photodynamic therapy with the phthalocyanine photosensitizer Pc 4 of SW 480 human colon cancer xenografts in athymic mice," Clinical Cancer Research, vol. 6, no. 5, pp. 2021-2027, 2000.

[16] N. A. Thornberry and Y. Lazebnik, "Caspases: enemies within," Science, vol. 281, no. 5381, pp. 1312-1316, 1998.

[17] L. E. Broker, F. A. E. Kruyt, and G. Giaccone, "Cell death independent of caspases: a review," Clinical Cancer Research, vol. 11, no. 9, pp. 3155-3162, 2005.

[18] L. Xue, S. Chiu, and N. L. Oleinick, "Differential responses of Mcl-1 in photosensitized epithelial vs lymphoid-derived human cancer cells," Oncogene, vol. 24, no. 46, pp. 6987-6992, 2005.

[19] J. Shao, J. Xue, Y. Dai et al., "Inhibition of human hepatocellular carcinoma HepG2 by phthalocyanine photosensitiser ZnPcS2P2: ROS production, apoptosis, cell cycle arrest," European Journal of Cancer, vol. 48, pp. 2086-2096, 2012.

[20] C. M. H. Chan, P. Lo, S. Yeung, D. K. P. Ng, and W. Fong, "Photodynamic activity of a glucoconjugated silicon(IV) phthalocyanine on human colon adenocarcinoma," Cancer Biology and Therapy, vol. 10, no. 2, pp. 126-134, 2010.

[21] M. E. Rodriguez, P. Zhang, K. Azizuddin et al., "Structural factors and mechanisms underlying the improved photodynamic cell killing with silicon phthalocyanine photosensitizers directed to lysosomes versus mitochondria," Photochemistry and Photobiology, vol. 85, no. 5, pp. 1189-1200, 2009.

[22] H. Huang, X. Zhao, Y. Chen, R. Lu, and Y. Wu, "Apoptosis induced by $\mathrm{ZnPcH1}$-based photodynamic therapy in Jurkat cells and HEL cells," International Journal of Hematology, vol. 94, no. 6, pp. 539-544, 2011.

[23] H. Y. Wu, W. Chen, T. Li, Y. Wang, C. H. Xia, and X. L. $\mathrm{Li}$, "Study on synthesis and antineoplastic activity of $\alpha$-tetra(4-carboxyphenoxy)phthalocyanine zinc," Journal of Liaoning Normal University. Natural Science Edition, vol. 32, pp. 94-97, 2009.

[24] M. C. Bi, R. Rosen, R. Y. Zha, S. A. McCormick, E. Song, and D. N. Hu, "Zeaxanthin induces apoptosis in human uveal melanoma cells through $\mathrm{Bcl}-2$ family proteins and intrinsic apoptosis pathway," Evidence-Based Complementary and Alternative Medicine, vol. 2013, Article ID 205082, 12 pages, 2013.

[25] A. M. M. Kober, S. Legewie, C. Pforr et al., "Caspase-8 activity has an essential role in CD95/Fas-mediated MAPK activation," Cell Death and Disease, vol. 2, no. 10, article e212, 2011.

[26] S. J. Kang, B. M. Kim, Y. J. Lee, S. H. Hong, and H. W. Chung, "Titanium dioxide nanoparticles induce apoptosis through the JNK/p38-caspase-8-Bid pathway in phytohemagglutininstimulated human lymphocytes," Biochemical and Biophysical Research Communications, vol. 386, no. 4, pp. 682-687, 2009.

[27] L. D. Huong, J.-A. Shin, E.-S. Choi et al., “ $\beta$-phenethyl isothiocyanate induces death receptor 5 to induce apoptosis in human oral cancer cells via p38," Oral Diseases, vol. 18, no. 5, pp. 513519, 2012.

[28] L. Yuan, J. Wang, H. Xiao, W. Wu, Y. Wang, and X. Liu, "MAPK signaling pathways regulate mitochondrial-mediated apoptosis induced by isoorientin in human hepatoblastoma cancer cells," Food and Chemical Toxicology, vol. 53, pp. 62-68, 2013.
[29] J. Yu, Z. Zheng, Y. Son, X. Shi, Y. Jang, and J. Lee, "Mycotoxin zearalenone induces AIF- and ROS-mediated cell death through p53- and MAPK-dependent signaling pathways in RAW264.7 macrophages," Toxicology in Vitro, vol. 25, no. 8, pp. 1654-1663, 2011.

[30] L. Cipak, "Novel nonclassical antifolate, 2-[N-(2'Hydroxyethyl)amino]methyl-3H-quinazolin-4-one, with a potent antineoplastic activity toward leukemia cells," Neoplasma, vol. 59, pp. 641-649, 2012.

[31] H. J. Cho, S. Y. Park, E. J. Kim, J. Kim, and J. H. Y. Park, “3,3”diindolylmethane inhibits prostate cancer development in the transgenic adenocarcinoma mouse prostate model," Molecular Carcinogenesis, vol. 50, no. 2, pp. 100-112, 2011.

[32] M. Lin, Y. Lu, H. Su et al., "Destabilization of CARP mRNAs by aloe-emodin contributes to caspase-8-mediated p53-independent apoptosis of human carcinoma cells," Journal of Cellular Biochemistry, vol. 112, no. 4, pp. 1176-1191, 2011.

[33] J. J. Choi, O. Kwon, S. Oh, H. Lee, and K. Ahn, "The effect of isolancifolide on the apoptosis in HL-60 cells through caspase-8-dependent and -independent pathways," Archives of Pharmacal Research, vol. 35, no. 1, pp. 137-143, 2012. 

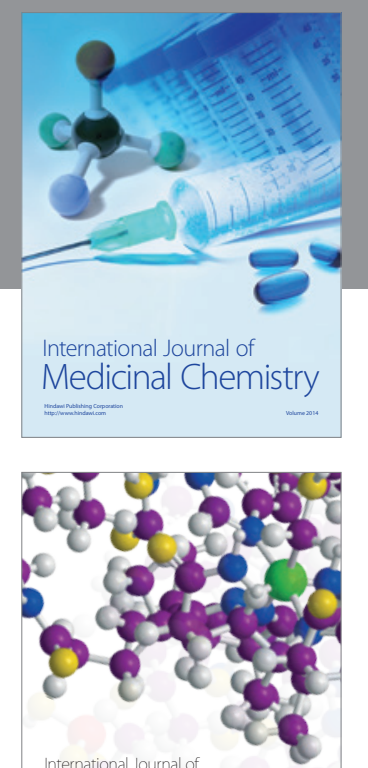

\section{Carbohydrate} Chemistry

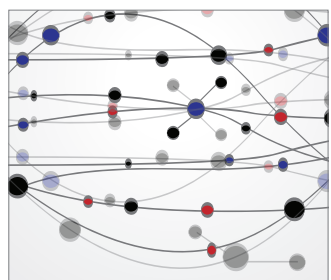

The Scientific World Journal
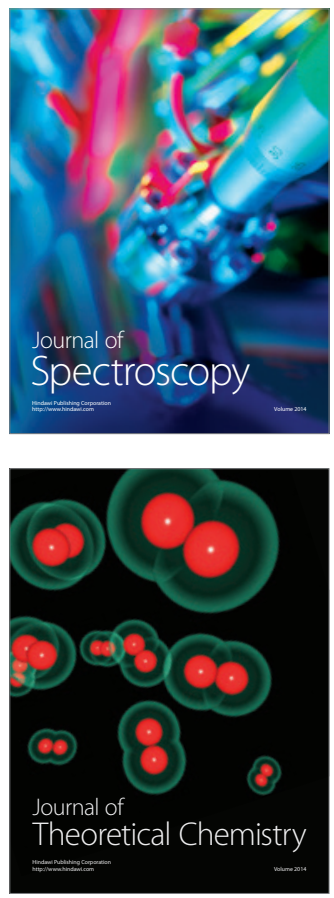
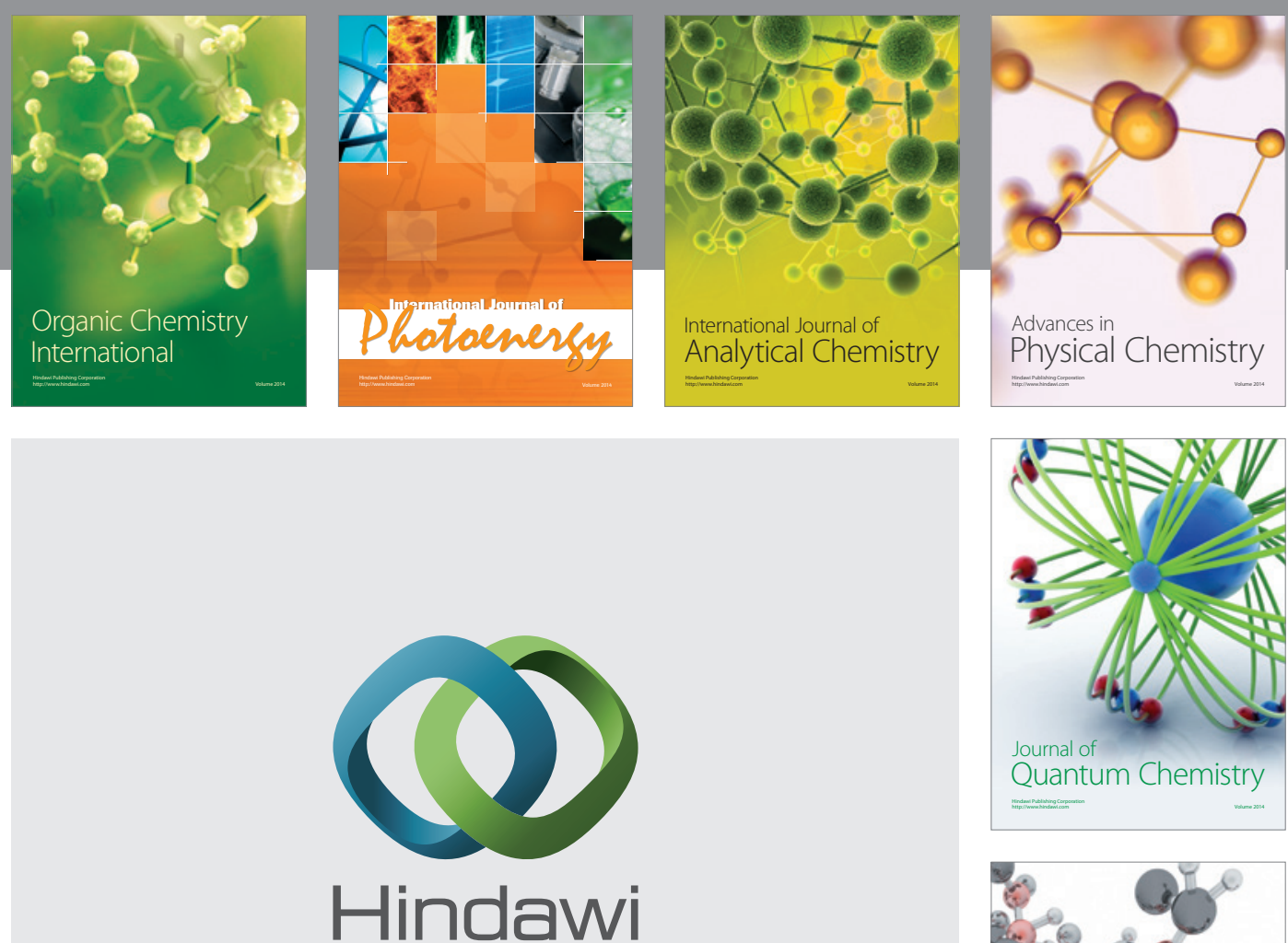

Submit your manuscripts at

http://www.hindawi.com

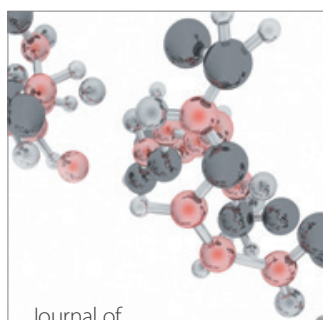

Analytical Methods

in Chemistry

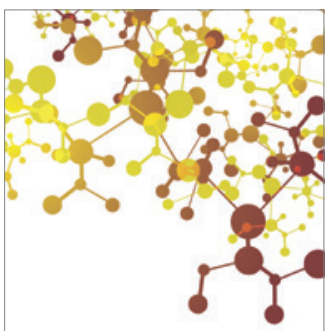

Journal of

Applied Chemistry

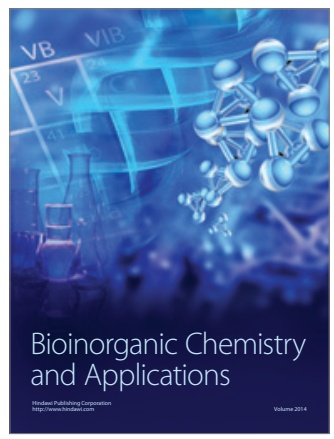

Inorganic Chemistry
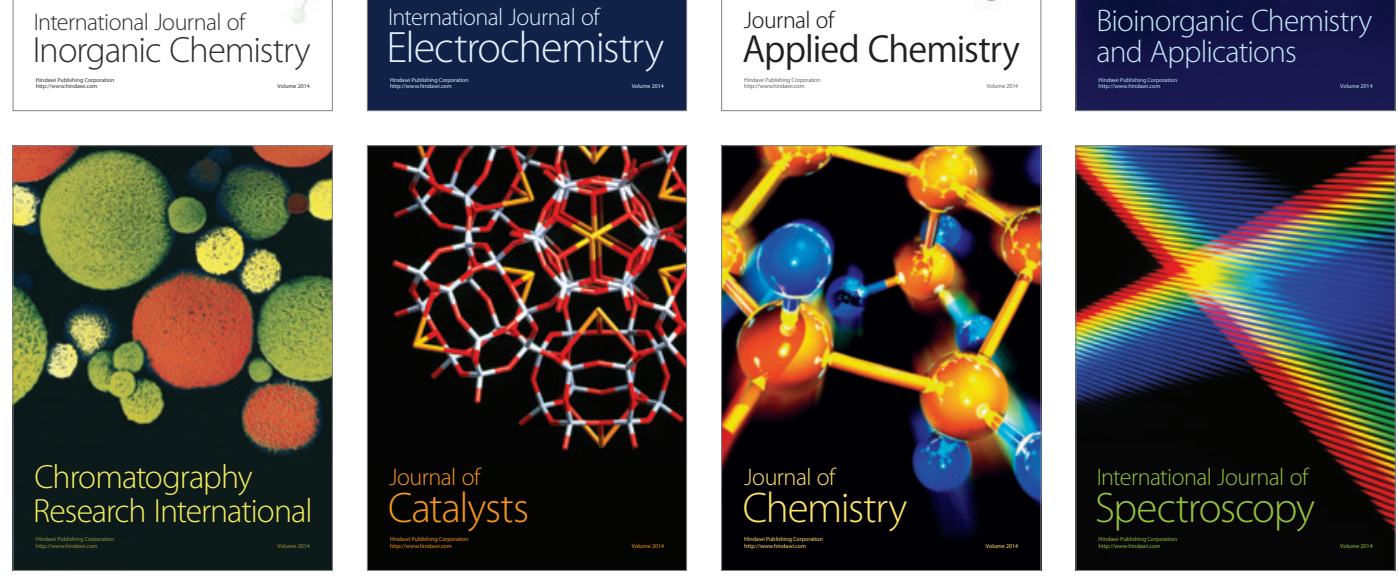